\title{
Efficacy Comparison of Tigecycline and Polymyxin B Against Carbapenem-Resistant Klebsiella Pneumoniae Infection in Intensive Care Units, a Multicenter Retrospective Study
}

\section{Buyao Zhang}

Department of Critical Care Medicine区 Xiangya Hospital of Central South University

Chenghuan $\mathrm{Hu}$

Department of Critical Care Medicine区 Xiangya Hospital of Central South University

\section{Fuxing Deng}

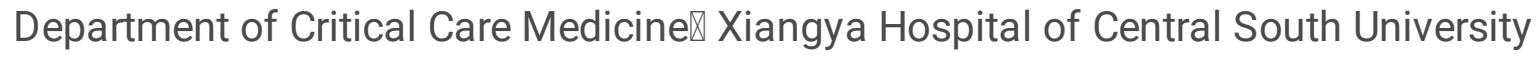

\section{Mingxia Li}

Department of Critical Care Medicine区 Xiangya Hospital of Central South University

\section{Ying Wu}

The Second Xiangya Hospital of Central South University

\section{Xuefei Xiao}

The Third Xiangya Hospital of Central South University

\section{Xu Zhou}

Hunan Provincial People's Hospital

\section{Yanhong Wu}

Hunan Provincial People's Hospital

\section{Yanjun Zhong}

The Second Xiangya Hospital of Central South University

\section{Shanshan Yan}

The Third Xiangya Hospital of Central South University

Shuangping Zhao ( $\sim$ zhshping@csu.edu.cn )

Department of Critical Care Medicine区 Xiangya Hospital of Central South University

\section{Research Article}

Keywords: Tigecycline1, Polymyxin B2, Intensive care unit3, Carbapenem-resistant Klebsiella pneumoniae 4, Efficacy5

Posted Date: February 14th, 2022 
DOI: https://doi.org/10.21203/rs.3.rs-1303820/v1

License: (c) (1) This work is licensed under a Creative Commons Attribution 4.0 International License. Read Full License 


\section{Abstract}

Aim: To investigate the efficacy of Tigecycline (TG) or polymyxin $\mathrm{B}(\mathrm{PB})$ against Carbapenem-resistant Klebsiella pneumoniae (CRKP) infection in ICUs.

Method: Electronic medical record systems were used to capture CRKP-infected patients who were treated with TG- or PB-based therapies from ICUs of four academic hospitals in Hunan, China. Propensity-score matching and logistic regression were used to compare efficacy and find prognostic factors.

Results: Of the 236 patients, 106 received TG-based therapy (TG), 102 received PB-based therapy (PB), and 28 received a combination of TG and PB (TG+PB). PB group showed higher CRKP clearance $(46.6 \%$ vs. $22.4 \%, P=0.011)$ and complete bacterial clearance $(32.8 \%$ vs. $15.5 \%, P=0.051)$ than TG group. CRKP clearance (OR $0.312,95 \% \mathrm{Cl} 0.159-0.612, P=0.001)$, longer duration of PB (4-8 vs. > 8 days, OR 2.974, $95 \% \mathrm{Cl} 1.297-6.820, P=0.010)$, and less vasoactive agents (1-4 vs. 0 days, OR 2.903, 95\% Cl 1.146-7.352, $P=0.025)$ were independent protective factors for 30-day mortality.

Conclusions: About CRKP treatment in ICUs, PB-based therapy showed better bacterial clearance than TGbased therapy. CRKP clearance, longer duration of $\mathrm{PB}$, and less vasoactive agents were independent protective factors for 30-day mortalit.

\section{Introduction}

Carbapenem-resistant Klebsiella pneumoniae (CRKP) infection is a pressing problem worldwide, especially in intensive care units (ICUs) [1]. It is frequently seen in respiratory tract, blood, abdomen, urinary tract infections, and others. For identified K. pneumoniae, CRKP has a detection rate of $>75 \%$ and a high mortality rate (48.9\%) in ICUs [2].

Tigecycline (TG) and polymyxin B (PB) have become the main and only antibiotics for the treatment of CRKP infections due to their lowest resistance[3]. They are often combined with other antibiotics for more efficacious CRKP treatment, such as carbapenems, cephalosporins, and sulbactam[4-6]. Three types of therapies are commonly used. TG-based therapy is TG in combined with other antibiotics except PB, PB-based therapy refers to PB in combined with other antibiotics except TG, and TG+PB-based therapy is the concomitant use of TG, PB, and any others. Sun et al. reported similar mortality of patients with TG (61.5\%) or PB (60.0\%)-based therapies[7]. Another retrospective study found PB-based therapy had a better survival rate than TG-based therapy[8]. In vitro experiments, the synergistic and/or cumulative antibacterial effects of TG+ceftazidime avibatan or (imipenem, fosfomycin), PB+TG or (ceftazidime avibatan, fosfomycin) and TG+PB +imipenem were $87.5 \%(68.8 \%, 62.5 \%), 100.0 \%(75.0 \%, 68.8 \%)$ and $75.0 \%$ respectively[9].

The optimal strategy of TG and PB (especially for critical illness in ICUs) is still unclear[10]. Comparative studies of the efficacy of TG and PB in the treatment of CRKP have mainly been in vitro or focused on a single site of infection (e.g., blood, urine) $[11,12]$. Moreover, the mortality of CRKP in ICUs remains very 
high even with the use of TG or PB, both of which are considered to be the "last line of defense" against CRKP [13-18]. It might be related to the characteristics of ICU patients, who are more severely ill, have multiple infections, pre-existing immunosuppression, and more surgical procedures, or invasive therapies[19]. Therefore, more studies are needed to explore the best strategy of treating CRKP with TG or PB and to improve the dismal outcome in ICUs.

To summarize the characteristics of CRKP-infected patients with TG-based, PB-based, or TG+PB-based therapies and to explore the risk factors of mortality. A multicenter retrospective study of patients with CRKP infection in ICUs was undertaken among four Grade 3A teaching hospitals in Hunan Province, China.

\section{Methods}

\section{Patients}

This study cohort comprised patients with CRKP infection from May 2017 to March 2021 in the ICUs of the First, Second and Third Xiangya Hospitals of Central South University, and Hunan Provincial People's Hospital, all of which are in Changsha, China.

Inclusion criteria were: (i) CRKP infected patients treated with TG (Pfizer Pharmaceuticals, New York, NY, USA) or PB (Shanghai Number 1 Biochemical \& Pharmaceuticals, China); (ii) The duration of TG or PB treatment was $\geq 96 \mathrm{~h}$; (iii) CRKP infection was clarified by bacteremia culture and susceptibility testing. In the case of patients with $\geq 2$ episodes of CRKP, only the first one was included. Exclusion criteria were: (i) Patients $₫ 18$ years; (ii) Dying patients as the efficacy was difficult to assess; (iii) cases with incomplete clinical data.

\section{Collection of clinical data}

The basic information of patients (age; gender; underlying diseases; baseline creatinine level in serum; requirement and duration of mechanical ventilation; requirement and duration of vasoactive drugs; Acute Physiology And Chronic Health Evaluation (APACHE) II score; Sequential Organ Failure Assessment (SOFA) score; diagnoses) was obtained. Information on the pathogens (source and species) and antibiotic regimens (treatment duration, dose, and frequency) and treatment results (in-hospital mortality, 30-day mortality, CRKP clearance, length of hospital stay (days), ICU duration (days), hospitalization costs) were also obtained. If patients had multiple episodes of CRKP infection and were then treated with PB or TG, only the first episode was included in our analyses.

\section{Research design}


Patients were divided into three groups according to the drug regimen: (i) TG-based therapy (TG group), defined as therapy in which TG is combined with any other antibiotic except $\mathrm{PB}$, and the duration of treatment was $\geq 96 \mathrm{~h}$. (ii) PB-based therapy (PB group) defined as therapy in which PB was combined with any other antibiotic except TG and the duration of PB treatment was $\geq 96 \mathrm{~h}$. (iii) TG+PB-based therapy (TG+PB group) defined as therapy in which TG, PB and any other are used together and the duration of treatment was $\geq 96 \mathrm{~h}$. "In-hospital mortality" was defined as death in hospital or, in severe cases, discontinuation of treatment due to poor prognosis. CRKP clearance was defined as the clearance of CRKP by culture during antibiotic therapy. Complete bacterial clearance was defined as the clearance of any pathogenic bacteria by culture.

\section{Microbiology}

Blood, alveolar lavage fluid, surgical drain, ascites, sputum, and catheter tip culture were sampled. Types of bacteria and minimum inhibitory concentrations (MICs) were determined by a VITEK®2 system (bioMérieux, Marcy-l'Étoile, France) according to the Clinical and Laboratory Standards Institute (CLSI, 2018) criteria [20]. CRKP was the dominant bacterium in bacterial culture with an MIC of $\geq 4 \mathrm{mg} / \mathrm{L}$ for meropenem/imipenem.

\section{Statistical analyses}

We used SPSS v21.0 (IBM, Armonk, NY, USA) and R 4.0.5 (R Institute for Statistical Computing, Vienna, Austria) for data analyses. Normally distributed data were expressed as mean \pm SD and evaluated by the Student's $t$-test or one-way analysis of variance. Data with non-normal distributions were expressed by median values and interquartile range (IQR) and analyzed by non-parametric tests. Count data were expressed by numbers and percentages, and evaluated by the chi-square test. Propensity-score matching (PSM) was used to control the difference in baseline characteristics between the PB group and TG group to observe the efficacy differences. The PSM ratio was $1: 1$ without replacement, and the caliper was 0.2 with the nearest methed. Binary logistic regression was applied to find confounding factors of 30-d mortality and bacterial clearance. Cox-regression analysis was employed to compare 30-day mortality across therapies for CRKP infection and the factors influencing it. Forward: LR was used in the logistic regression. All analyses were two-tailed, and $P<0.05$ was considered significant.

\section{Results}

\section{Characteristics of the study cohort}

Of the 236 patients, the median age was 55 years. The majority of them were male (78.8\%). $35.2 \%$ had cardiovascular disease, $86.0 \%$ were on mechanical ventilation, $70.3 \%$ were taking vasoactive drugs, and $52.5 \%$ were suffering from sepsis shock. The median score for APACHE II and SOFA at baseline were 20 and 8 , respectively. The incidence of in-hospital mortality and 30 -day mortality were $46.6 \%$ and $40.7 \%$, 
respectively. The total bacterial clearance rate was $22.9 \%$ (54/236) compared to $36.9 \%(87 / 236)$ for CRKP clearance. Additionally, 106 (44.9\%) received TG (TG group), 102 (43.2\%) received PB (PB group), and $28(11.9 \%)$ received TG combined with PB (TG+PB group). Meropenem, imipenem, and sulbactam cephalosporin were mainly in combination. More men, middle-aged with pulmonary infections, multiple sites of infection, sepsis, unstable hemodynamics, critical illness, and high mortality characterized our cohort, which makes it different from those in other studies. The clinical characteristics of the patients are listed in Table 1.

\section{TG+PB group}

In the TG+PB group with 28 cases, $57.1 \%$ of the patients had multiple infection sites, $42.9 \%$ had blood infections. The median APACHE II score and SOFA score were 20.50 and 8.00, respectively (Table 2). The median serum creatinine level before and after treatment were $201.00 \mu \mathrm{mol} / \mathrm{L}$ and $165.5 \mu \mathrm{mol} / \mathrm{L}$, respectively. Moreover, $35.7 \%$ cleared CRKP, $10.7 \%$ cleared all bacteria, $64.3 \%$ died within 30 days, and the median 30-day survival was 16.50 days. The hospitalization cost was 56.09 thousand dollars. More critically ill may have masked some of the efficacy of TG+PB-based therapy. Because of the limit of the small sample size, comparsion analysis were not employed among TG+PB group and other groups.

\section{TG group vs. PB group}

The TG group had more patients with simple abdominal infection than those in the PB group $(19.8 \%$ vs. $8.8 \%, P=0.040)$. At baseline, patients in the TG group had a lower median APACHE II score (18.00 vs. $20.00, P=0.001)$, SOFA score $(6.50 \mathrm{vs} .8 .00, P<0.001)$ and more of them were taking vasoactive agents (63.2\% vs. $79.4 \%, P=0.015)$. Regarding the secondary outcome, patients in the TG group took vasoactive agents for fewer days (2.50 vs. 5.00, $P=0.015)$, underwent mechanical ventilation for fewer days (6.00 vs. $13.00, P=0.003)$, and incurred lower hospitalization costs (40.28 vs. 50.80 thousand dollars, $P=0.003$ ) than those in the PB group. Concerning the primary outcome, fewer patients in the TG group were able to clear CRKP than those in the PB group ( $31.1 \%$ vs. $43.1 \%, P=0.073)$. The 30 -day mortality in the TG group was lower than that in the PB group (33.0\% vs. $42.2 \%, P=0.223)$, as was in-hospital mortality (37.7\% vs. 51.0\%, $P=0.075$ ) (Table 2 ).

Due to the differences of the baseline between TG and PB groups, propensity-score matching was performed to control the confounders. 58 pairs of cases were matched. After PSM, the baseline characteristics of the two groups were balanced, including the age, infection factors, therapy factors, underlying dieases, and other potential prognostic factors. The propensity-score were TG: $0.49 \pm 0.13 \mathrm{vs}$. PB: $0.49 \pm 0.13(P=0.975)$ (Figur 1$)$. PB group showed higher CRKP clearance $(46.6 \%$ vs. $22.4 \%, P=$ $0.011)$ and complete bacterial clearance $(32.8 \%$ vs. $15.5 \%, P=0.051)$ than TG group. PB group had lower 30-day mortality than TG group without statistical significance $(34.5 \%$ vs. $37.9 \%, P=0.847)$.

Furthermore, PB group showed more expensive hospital cost than TG group (Table 3). Why were bacterial 
clearance statistically significant, but 30-day mortality not? We taken binary logistic and COX regressions to verified further.

\section{Binary logistic regression of 30-day mortality}

Univariate analyses about 30-day mortality and bacterial clearance and subsequent logistic regression analysis were applied. The results indicated that age, septic shock, mechanical ventilation, vasoactive agents, and TG/PB treatment may be associated with different incidences of 30-day mortality (Supplementary Table 1). Binary logistic regression was performed to demonstrate these factors.

For 30-day mortality, CRKP clearance was an independent protective factor (OR $0.312,95 \% \mathrm{Cl} 0.159-0.612$, $P=0.001$ ). A shorter duration of $\mathrm{PB}$ was an independent risk factor compared to longer duration (4-8 days $v s$. $>8$ days, OR $2.974,95 \% \mathrm{Cl} 1.297-6.820, P=0.010)$. In addition, the duration of vasoactive agents was an independent risk factor (1-4 days vs. 0 days, $\mathrm{OR} 2.90,95 \% \mathrm{Cl} 1.146-7.352, P=0.025 ;>4$ days $v s .0$ days, $\mathrm{OR} 8.843,95 \% \mathrm{Cl} 3.845-22.338, P=0.000)$. No significant risk difference was found between TGbased and PB-based therapies (PB vs. TG, OR 0.554, 95\% Cl 0.096-3.210, $P=0.510$ ). (Table 4).

\section{Cox regression analysis for 30-day mortality}

Finally, Cox regression survival analyses were carried out to compare the incidence of 30-day mortality and survival. CRKP clearance $(P=0.000)$, longer duration of PB $(P=0.000)$ and less use of vasoactive agents $(P<0.050)$ were independent protective factors for 30-day cumulative survival. While the PB group had a better survival outcome than the TG group, the difference was not significant (PB vs. TG, OR, $0.858,95 \% \mathrm{Cl} 0.306-2.402, P=0.770$ ). (Table 5 and Figure 2).

\section{Discussion}

In this study, PB group had better bacterial clearance than TG group. CRKP clearance and longer duration of PB showed a lower risk for 30-day mortality and cumulative survival time, whlie vasoactive agents showed a higher risk. Furthermore, PB group had a heavier financial burden than TG group. TG+PB group had more critical underlying illness, complex infection, worse 30-day mortality and cumulative survival in univariate analyses.

\section{TG-based vs. PB-based therapies}

Papadimitriou-Olivgeris et al. also did not find any difference between the TG group and patients taking other antibiotic therapies for critically ill patients with CRKP infection in the blood, if the minimum inhibitory concentration (MIC) was $0.5 \mathrm{mg} / \mathrm{L}$ in 30-day mortality[15]. Similarly, in blood CRKP infection, PB failed to improve outcomes in patients who responded poorly to TG[7], suggesting that PB is not more efficacious than TG. Nevertheless, a retrospective study involving 89 cases of CRKP infection in blood 
showed a survival advantage for PB-based therapy compared with that using TG-based therapy[8]. A meta-analysis found that TG-based therapy was not suitable for CRE in blood infection because of its poor microbiological efficacy[21]. In carbapenem-resistant Acinetobacter baumannii pulmonary infection, patients receiving PE-based therapy had longer survival than those receiving TG-based therapy[22]. Furthermore, higher clearance of CRKP from urine has been reported with PB-based therapy compared to that with TG-based therapy (64\% and 43\%, respectively)[12]. In our study, the PB group showed better CRKP clearance than the TG group, but not survival benefits. Moreover, a longer duration of PB was a protective factors for 30-day mortality and cumulative survival time.

Why different these studies different? Heterogeneity between studies plays an important role in conflicting results. Firstly, multiple sites of infection are often overlooked when studies focus on a single site of infection. Patients often have definite and suspected CRKP infections at more than one site in the real world, especially in ICUs. How to deal with this bias has not been consistent in previous studies. Secondary, as most studies are observational, retrospective and small sample size studies, there is inevitably a significant selection bias in these studies. There are very few randomised controlled trials (RCTs).

\section{TG+PB-based therapy}

TG+PB-based therapy is also a common treatment strategy for CRKP in practice. Patients using this regimen have more critical underlying illnesses and complex infections. Due to the increasing number of in vitro. experiments in which synergistic and/or cumulative antimicrobial effects of TG+PB were observed [9, 23-25], it was hypothesized that TG combined with PB may improve the efficacy of patients with CRKP infection. On the contrary, the TG+PB group showed worse 30-day mortality and cumulative survival in univariate analyses. Due to the limitation of the small sample size, the TG+PB group cannot have a plausible result for logistic regression analysis. One possible explanation is that its efficacy may have been partially masked the critical illness. Some reviews have stated that more prospective studies are needed to draw firm conclusions $[10,26]$.

\section{Duration of PB}

A shorter duration of PB was found to be an independent risk factor for 30-day mortality compared with the longer one. There are very few studies that can be referenced. Only one study of PB efficacy in 191 patients with CRO infection showed that high total cumulative dose was an independent protective factor, suggesting a possible benefit regarding long duration [27]. Caution must be exercised when discussing and drawing conclusions.

\section{Vasoactive agents}


Duration of vasoactive agents was an independent risk factor for 30-day mortality and cumulative survival in our cohort. Similar results have been reported in previous studies [28]. It was also found in our study that risk increased with increasing days of use after we masked days as an ordinal categorical variable. Moreover, sepsis shock was found as a barrier to CRKP clearance in our study.

Therefore, hemodynamics is an important bias that should be balanced when the efficacy of TG-and/or PB-based therapies is compared. In addition, many other factors have been reported that may affect the outcome of CRKP infection, such as complications, APACHE II score, baseline serum creatinine level, coinfection, debridement, drainage, catheter removal, microbiologic eradication[28-31].

\section{Limit}

There are two main limitations to our study. First, the sample size in our four-center retrospective study on the TG+PB group was small and there were confounding factors. A larger study cohort and a prospective randomized study are needed to draw robust conclusions. Second, the clinical data of patients (e.g., weight, time from hospitalization to pathogen detection, time from pathogen detection to use of TG/PB, exposure to carbapenems, MIC of target TG/PB, drainage of infection site, immunosuppressive status) were not sufficiently detailed and may have affected our results.

\section{Conclusion}

About CRKP treatment in ICUs, PB-based therapy showed better bacterial clearance than TG-based therapy. CRKP clearance, and longer duration of PB were independent protective factors for 30-day mortality, while vasoactive agents were an independent risk factor. PB group showed better survival benefits than the TG group in clinic, but without statistically significance. Further prospective studies are extremely urgent.

\section{Declarations}

\section{Ethics approval and consent to participate}

This retrospective study involving human participants was in accordance with the ethical standards of the institutional and national research committee and with the 1964 Helsinki Declaration and its later amendments or comparable ethical standards. The Ethics Committee of Xiangya Hospital of Central South University (Changsha, China) approved this study (202105202). Informed consent to all participate in the study had been obtained from participants (or their parent or legal guardian in the case of children under 16).

\section{Consent for publication}

Not applicable. 


\section{Availability of data and materials}

The datasets generated and/or analysed during the current study are not publicly available for involving human participants but are available from the corresponding author on reasonable request.

\section{Funding}

This work was supported by the National Key Research and Development Program of China (2020YFC2005403) and the WU JIEPING Medical Foundation (320.6750.18425).

\section{Author contributions}

All authors contributed to the study conception and design. Material preparation, data collection and analysis were performed by BZ, CH, ML, FD, YZ and SY. The first draft of the manuscript was written by BZ. SZ, YW, XX, XZ, and YW modified relevant contents including language and initial draft responding to reviewers. All authors read and approved the final manuscript.

\section{Conflict of interest}

The authors declare that they have no conflict of interest.

\section{Acknowledgements}

Not applicable.

\section{References}

1. Zhang Y, Wang Q, Yin Y, Chen H, Jin L, Gu B, et al. Epidemiology of Carbapenem-Resistant Enterobacteriaceae Infections: Report from the China CRE Network. Antimicrob Agents Chemother. 2018;62(2). https://doi.org/10.1128/aac.01882-17.

2. Xu L, Sun X, Ma X. Systematic review and meta-analysis of mortality of patients infected with carbapenem-resistant Klebsiella pneumoniae. Ann Clin Microbiol Antimicrob. 2017;16(1):18. https://doi.org/10.1186/s12941-017-0191-3.

3. Han R, Shi Q, Wu S, Yin D, Peng M, Dong D, et al. Dissemination of Carbapenemases (KPC, NDM, OXA-48, IMP, and VIM) Among Carbapenem-Resistant Enterobacteriaceae Isolated From Adult and Children Patients in China. Front Cell Infect Microbiol. 2020;10:314. https://doi.org/10.3389/fcimb.2020.00314. 
4. Yaghoubi S, Zekiy AO, Krutova M, Gholami M, Kouhsari E, Sholeh M, et al. Tigecycline antibacterial activity, clinical effectiveness, and mechanisms and epidemiology of resistance: narrative review. European journal of clinical microbiology \& infectious diseases : official publication of the European Society of Clinical Microbiology. 2021:1-20. https://doi.org/10.1007/s10096-020-04121-1.

5. Lu Q, Zhu HH, Li GH, Qi TT, Ye LJ, Teng XQ, et al. A Comparative Study of the Microbiological Efficacy of Polymyxin B on Different Carbapenem-Resistant Gram-Negative Bacteria Infections. Frontiers in medicine. 2021;8:620885. https://doi.org/10.3389/fmed.2021.620885.

6. Nang SC, Azad MAK, Velkov T, Zhou QT, Li J. Rescuing the Last-Line Polymyxins: Achievements and Challenges. Pharmacol Rev. 2021;73(2):679-728. https://doi.org/10.1124/pharmrev.120.000020.

7. Sun WM, Zhou H, Shen LS, Yang Q, Ma WJ, Zhou JY. [The efficacy and safety of different antimicrobial regimens in carbapenem-resistant Klebsiella pneumoniae bloodstream infections]. Zhonghua Nei Ke Za Zhi. 2019;58(8):566-71. https://doi.org/10.3760/cma.j.issn.05781426.2019.08.004.

8. Shen L, Lian C, Zhu B, Yao Y, Yang Q, Zhou J, et al. Bloodstream Infections due to CarbapenemResistant Klebsiella pneumoniae: A Single-Center Retrospective Study on Risk Factors and Therapy Options. Microbial drug resistance (Larchmont, NY). 2021;27(2):227-33. https://doi.org/10.1089/mdr.2019.0455.

9. Yao H, Liu J, Jiang X, Chen F, Lu X, Zhang J. Analysis of the Clinical Effect of Combined Drug Susceptibility to Guide Medication for Carbapenem-Resistant Klebsiella pneumoniae Patients Based on the Kirby-Bauer Disk Diffusion Method. Infection and drug resistance. 2021;14:79-87. https://doi.org/10.2147/idr.S282386.

10. Durante-Mangoni E, Andini R, Zampino R. Management of carbapenem-resistant Enterobacteriaceae infections. Clinical microbiology and infection : the official publication of the European Society of Clinical Microbiology and Infectious Diseases. 2019;25(8):943-50. https://doi.org/10.1016/j.cmi.2019.04.013.

11. Liang Q, Huang $M, X u Z$. Early use of polymyxin B reduces the mortality of carbapenem-resistant Klebsiella pneumoniae bloodstream infection. Braz J Infect Dis. 2019;23(1):60-5. https://doi.org/10.1016/j.bjid.2018.12.004.

12. Satlin MJ, Kubin CJ, Blumenthal JS, Cohen AB, Furuya EY, Wilson SJ, et al. Comparative effectiveness of aminoglycosides, polymyxin $B$, and tigecycline for clearance of carbapenemresistant Klebsiella pneumoniae from urine. Antimicrob Agents Chemother. 2011;55(12):5893-9. https://doi.org/10.1128/aac.00387-11.

13. Liu P, Li X, Luo M, Xu X, Su K, Chen S, et al. Risk Factors for Carbapenem-Resistant Klebsiella pneumoniae Infection: A Meta-Analysis. Microbial drug resistance (Larchmont, NY). 2018;24(2):1908. https://doi.org/10.1089/mdr.2017.0061.

14. Li J, Li Y, Song N, Chen Y. Risk factors for carbapenem-resistant Klebsiella pneumoniae infection: A meta-analysis. J Glob Antimicrob Resist. 2020;21:306-13. https://doi.org/10.1016/j.jgar.2019.09.006. 
15. Papadimitriou-Olivgeris M, Bartzavali C, Nikolopoulou A, Kolonitsiou F, Mplani V, Spiliopoulou I, et al. Impact of Tigecycline's MIC in the Outcome of Critically III Patients with Carbapenemase-Producing Klebsiella pneumoniae Bacteraemia Treated with Tigecycline Monotherapy-Validation of 2019's EUCAST Proposed Breakpoint Changes. Antibiotics (Basel). 2020;9(11). https://doi.org/10.3390/antibiotics9110828.

16. Rigatto MH, Falci DR, Zavascki AP. Clinical Use of Polymyxin B. Adv Exp Med Biol. 2019;1145:197218. https://doi.org/10.1007/978-3-030-16373-0_14.

17. Doi Y. Treatment Options for Carbapenem-resistant Gram-negative Bacterial Infections. Clin Infect Dis. 2019;69(Suppl 7):S565-s75. https://doi.org/10.1093/cid/ciz830.

18. Zusman O, Altunin S, Koppel F, Dishon Benattar Y, Gedik H, Paul M. Polymyxin monotherapy or in combination against carbapenem-resistant bacteria: systematic review and meta-analysis. $J$ Antimicrob Chemother. 2017;72(1):29-39. https://doi.org/10.1093/jac/dkw377.

19. Zuo Y, Zhao D, Song G, Li J, Xu Y, Wang Z. Risk Factors, Molecular Epidemiology, and Outcomes of Carbapenem-Resistant Klebsiella pneumoniae Infection for Hospital-Acquired Pneumonia: A Matched Case-Control Study in Eastern China During 2015-2017. Microbial drug resistance (Larchmont, NY). 2021;27(2):204-11. https://doi.org/10.1089/mdr.2020.0162.

20. Humphries RM, Ambler J, Mitchell SL, Castanheira M, Dingle T, Hindler JA, et al. CLSI Methods Development and Standardization Working Group Best Practices for Evaluation of Antimicrobial Susceptibility Tests. J Clin Microbiol. 2018;56(4). https://doi.org/10.1128/jcm.01934-17.

21. Kengkla K, Kongpakwattana K, Saokaew S, Apisarnthanarak A, Chaiyakunapruk N. Comparative efficacy and safety of treatment options for MDR and XDR Acinetobacter baumannii infections: a systematic review and network meta-analysis. J Antimicrob Chemother. 2018;73(1):22-32. https://doi.org/10.1093/jac/dkx368.

22. Chuang YC, Cheng CY, Sheng WH, Sun HY, Wang JT, Chen YC, et al. Effectiveness of tigecyclinebased versus colistin- based therapy for treatment of pneumonia caused by multidrug-resistant Acinetobacter baumannii in a critical setting: a matched cohort analysis. BMC Infect Dis. 2014;14:102. https://doi.org/10.1186/1471-2334-14-102.

23. Ku YH, Chen CC, Lee MF, Chuang YC, Tang HJ, Yu WL. Comparison of synergism between colistin, fosfomycin and tigecycline against extended-spectrum $\beta$-lactamase-producing Klebsiella pneumoniae isolates or with carbapenem resistance. J Microbiol Immunol Infect. 2017;50(6):931-9. https://doi.org/10.1016/j.jmii.2016.12.008.

24. Tsala M, Vourli S, Georgiou PC, Pournaras S, Daikos GRL, Mouton JW, et al. Triple combination of meropenem, colistin and tigecycline was bactericidal in a dynamic model despite mere additive interactions in chequerboard assays against carbapenemase-producing Klebsiella pneumoniae isolates. J Antimicrob Chemother. 2019;74(2):387-94. https://doi.org/10.1093/jac/dky422.

25. De Pascale G, Martucci G, Montini L, Panarello G, Cutuli SL, Di Carlo D, et al. Double carbapenem as a rescue strategy for the treatment of severe carbapenemase-producing Klebsiella pneumoniae 
infections: a two-center, matched case-control study. Crit Care. 2017;21(1):173.

https://doi.org/10.1186/s13054-017-1769-z.

26. Jacobs DM, Safir MC, Huang D, Minhaj F, Parker A, Rao GG. Triple combination antibiotic therapy for carbapenemase-producing Klebsiella pneumoniae: a systematic review. Ann Clin Microbiol Antimicrob. 2017;16(1):76. https://doi.org/10.1186/s12941-017-0249-2.

27. Lu Q, Li GH, Qu Q, Zhu HH, Luo Y, Yan H, et al. Clinical Efficacy of Polymyxin B in Patients Infected with Carbapenem-Resistant Organisms. Infection and drug resistance. 2021;14:1979-88. https://doi.org/10.2147/idr.S312708.

28. Zhang H, Guo Z, Chai Y, Fang YP, Mu X, Xiao N, et al. Risk Factors for and Clinical Outcomes of Carbapenem-Resistant Klebsiella pneumoniae Nosocomial Infections: A Retrospective Study in a Tertiary Hospital in Beijing, China. Infection and drug resistance. 2021;14:1393-401. https://doi.org/10.2147/idr.S298530.

29. Liu KS, Tong YS, Lee MT, Lin HY, Lu MC. Risk Factors of 30-Day All-Cause Mortality in Patients with Carbapenem-Resistant Klebsiella pneumoniae Bloodstream Infection. J Pers Med. 2021;11(7). https://doi.org/10.3390/jpm11070616.

30. Vardakas KZ, Matthaiou DK, Falagas ME, Antypa E, Koteli A, Antoniadou E. Characteristics, risk factors and outcomes of carbapenem-resistant Klebsiella pneumoniae infections in the intensive care unit. J Infect. 2015;70(6):592-9. https://doi.org/10.1016/j.jinf.2014.11.003.

31. Zhang P, Wang J, Hu H, Zhang S, Wei J, Yang Q, et al. Clinical Characteristics and Risk Factors for Bloodstream Infection Due to Carbapenem-Resistant Klebsiella pneumoniae in Patients with Hematologic Malignancies. Infection and drug resistance. 2020;13:3233-42. https://doi.org/10.2147/idr.S272217.

\section{Tables}

Table 1 Clinical characteristics of CRKP-infected patients with TG- or PB-based therapies 


\begin{tabular}{|c|c|}
\hline Variable & Total $(n=236)$ \\
\hline Male & $186(78.8)$ \\
\hline Age (years) & $55.00(43.00,66.00)$ \\
\hline \multicolumn{2}{|l|}{ Infection site } \\
\hline Abdomen & $85(36.0)$ \\
\hline Only abdomen & $34(14.4)$ \\
\hline Lung & $171(72.5)$ \\
\hline Only lung & $90(38.1)$ \\
\hline Blood & $61(25.8)$ \\
\hline Only blood & $15(6.4)$ \\
\hline Central nervous system & $6(2.5)$ \\
\hline Urinary tract & $6(2.5)$ \\
\hline Skin & $7(3.0)$ \\
\hline Multiple sites & $90(38.1)$ \\
\hline \multicolumn{2}{|l|}{ Underlying disease } \\
\hline Respiratory system & $21(8.9)$ \\
\hline Cardiovascular & $83(35.2)$ \\
\hline Kidney damage & $29(12.3)$ \\
\hline Liver damage & $27(11.4)$ \\
\hline Diabetes mellitus & $42(17.8)$ \\
\hline Tumors & $13(5.5)$ \\
\hline $\mathrm{sCr}(\mu \mathrm{mol} / \mathrm{L})$ & $118.50(72.00,239.00)$ \\
\hline APACHE II score & $20.00(15.00,24.00)$ \\
\hline SOFA score & $8.00(4.75,9.00)$ \\
\hline Mechanical ventilation & $203(86.0)$ \\
\hline Vasoactive agents & $166(70.3)$ \\
\hline Duration of vasoactive-agent use (days) & $4.00(0.00,10.00)$ \\
\hline Duration of mechanical ventilation (days) & $10.00(3.00,18.25)$ \\
\hline Septic shock & $124(52.5)$ \\
\hline
\end{tabular}




\begin{tabular}{|c|c|}
\hline \multicolumn{2}{|l|}{ Primary outcome } \\
\hline 30-day mortality & $96(40.7)$ \\
\hline In-hospital mortality & $110(46.6)$ \\
\hline Total bacterial clearance & $54(22.9)$ \\
\hline CRKP clearance & $87(36.9)$ \\
\hline \multicolumn{2}{|l|}{ Secondary outcome } \\
\hline $\mathrm{sCr}(\mu \mathrm{mol} / \mathrm{L})$ & $105.00(63.00,176.25)$ \\
\hline Hospitalization duration (days) & $33.00(20.75,47.25)$ \\
\hline Duration of ICU stay (days) & $20.50(13.00,30.00)$ \\
\hline Hospitalization cost (\$, Thousand) & $47.33(31.75,65.76 \rrbracket$ \\
\hline 30-day survival (days) & $30.00(11.00,30.00)$ \\
\hline
\end{tabular}

sCr, Serum creatinine; TG, Tigecycline; PB, polymyxin. In-hospital mortality, the percentage of patients who died in the hospital or discontinued treatment due to poor efficacy. Significant differences are emboldened.

Table 2 Comparison of characteristics of CRKP-infected patients undergoing different therapies 


\begin{tabular}{|c|c|c|c|c|}
\hline Variable & $\mathrm{TG}(\mathrm{n}=106)$ & $P B(n=102)$ & $\mathrm{TG}+\mathrm{PB}(\mathrm{n}=28)$ & $P 12$ \\
\hline Male & $86(81.1)$ & $79(77.5)$ & $21(75.0)$ & 0.628 \\
\hline Age (years) & $\begin{array}{l}55.00(43.25 \\
65.75)\end{array}$ & $\begin{array}{l}59.00(45.00 \\
68.50)\end{array}$ & $\begin{array}{l}48.50(38.00 \\
62.50)\end{array}$ & 0.327 \\
\hline \multicolumn{5}{|l|}{ Infection site } \\
\hline Abdomen & $41(38.7)$ & 33 (32.4) & $11(39.3)$ & 0.419 \\
\hline Only abdomen & $21(19.8)$ & $9(8.8)$ & $4(14.3)$ & $0.040 *$ \\
\hline Lung & $74(69.8)$ & $76(74.5)$ & $21(75.0)$ & 0.548 \\
\hline Only lung & $44(41.5)$ & $39(38.2)$ & $7(25.0)$ & 0.734 \\
\hline Blood & $20(18.9)$ & $29(28.4)$ & $12(42.9)$ & 0.144 \\
\hline Only blood & $6(5.7)$ & $8(7.8)$ & $1(3.6)$ & 0.725 \\
\hline $\begin{array}{l}\text { Central nervous } \\
\text { system }\end{array}$ & $2(1.9)$ & $4(3.9)$ & $0(0.0)$ & 0.439 \\
\hline Urinary tract & $1(0.9)$ & $3(2.9)$ & $2(7.1)$ & 0.362 \\
\hline Skin & $2(1.9)$ & $4(3.9)$ & $1(3.6)$ & 0.439 \\
\hline Multiple sites & $32(30.2)$ & $42(41.2)$ & $16(57.1)$ & 0.131 \\
\hline \multicolumn{5}{|l|}{ Underlying disease } \\
\hline Respiratory system & $12(11.3)$ & $8(7.8)$ & $1(3.6)$ & 0.538 \\
\hline Cardiovascular & $41(38.7)$ & $36(35.3)$ & $6(21.4)$ & 0.717 \\
\hline Kidney damage & $17(16)$ & $11(10.8)$ & $1(3.6)$ & 0.365 \\
\hline Liver damage & $8(7.5)$ & $15(14.7)$ & $4(14.3)$ & 0.154 \\
\hline Diabetes mellitus & $20(18.9)$ & $18(17.6)$ & $4(14.3)$ & 0.961 \\
\hline Tumors & $7(6.6)$ & $6(5.9)$ & $0(0.0)$ & 1 \\
\hline $\mathrm{sCr}(\mu \mathrm{mol} / \mathrm{L})$ & $\begin{array}{l}105.5(72.0 \\
225.0)\end{array}$ & $\begin{array}{l}130.5(71.0 \\
241.0)\end{array}$ & $\begin{array}{l}201.0(97.5 \\
254.0)\end{array}$ & 0.615 \\
\hline APACHE II score & $\begin{array}{l}18.00(13.00 \\
22.00)\end{array}$ & $\begin{array}{l}20.00(16.25 \\
27.75)\end{array}$ & $\begin{array}{l}20.50(15.00 \\
25.00)\end{array}$ & $0.001 *$ \\
\hline SOFA score & $6.50(4.00,8.00)$ & $8.00(7.00,10.00)$ & $8.00(5.50,8.25)$ & $\begin{array}{l}0.001 \text { * } \\
0.001 \text { * }\end{array}$ \\
\hline $\begin{array}{l}\text { Mechanical } \\
\text { ventilation }\end{array}$ & $92(86.8)$ & $87(85.3)$ & $24(85.7)$ & 0.911 \\
\hline Vasoactive agents & $67(63.2)$ & $81(79.4)$ & $18(64.3)$ & $0.015^{\star}$ \\
\hline
\end{tabular}




\begin{tabular}{|lllll|}
\hline Septic shock & $54(50.9)$ & $53(52.0)$ & $17(60.7)$ & 0.994 \\
\hline Therapy & & & & \\
\hline TG duration (days) & $9.00(6.25,14.75)$ & NA & $\begin{array}{l}11.00(8.00, \\
15.25)\end{array}$ & NA \\
\hline PB duration (days) & NA & $\begin{array}{l}10.00(7.00, \\
13.00)\end{array}$ & $\begin{array}{l}10.00(7.75, \\
16.25)\end{array}$ & NA \\
\hline TG 50 mg, q12 h & $55(51.9)$ & NA & $12(42.9)$ & NA \\
\hline TG 100 mg, q12 h & $51(48.1)$ & NA & $16(57.1)$ & NA \\
\hline PB 50 mg, q12 h & NA & $62(60.8)$ & $16(57.1)$ & NA \\
\hline PB 75 mg, q12 h & NA & $11(10.8)$ & $5(17.9)$ & NA \\
\hline PB $100 \mathrm{mg}$, q12 h & NA & $29(28.4)$ & $7(25)$ & NA \\
\hline
\end{tabular}

sCr, Serum creatinine; TG, Tigecycline; PB, polymyxin; P12, TG group and PB group. NA, not applicable, for example, PB group did not use tigecycline, so TG dose was "NA". *, significant differences.

Table 3 Comparison of characteristics of CRKP-infected patients after PSM 


\begin{tabular}{|c|c|c|c|c|}
\hline Variable & Total $(n=116)$ & $\mathrm{TG}(\mathrm{n}=58)$ & $P B(n=58)$ & $P$ \\
\hline Male & $87(75)$ & $44(75.9)$ & $43(74.1)$ & 1 \\
\hline Age (years) & $54.35 \pm 15.24$ & $53.6 \pm 15.2$ & $55.1 \pm 15.37$ & 0.598 \\
\hline \multicolumn{5}{|l|}{ Infection site } \\
\hline Abdomen & 38 (32.8) & $21(36.2)$ & $17(29.3)$ & 0.553 \\
\hline Only abdomen & $16(13.8)$ & $8(13.8)$ & $8(13.8)$ & 1 \\
\hline Lung & $84(72.4)$ & $43(74.1)$ & $41(70.7)$ & 0.835 \\
\hline Only lung & $48(41.4)$ & $23(39.7)$ & $25(43.1)$ & 0.85 \\
\hline Blood & $29(25)$ & $14(24.1)$ & $15(25.9)$ & 1 \\
\hline Only blood & $10(8.6)$ & $4(6.9)$ & $6(10.3)$ & 0.741 \\
\hline $\begin{array}{l}\text { Central nervous } \\
\text { system }\end{array}$ & $2(1.7)$ & $1(1.7)$ & $1(1.7)$ & 1 \\
\hline Urinary tract & $1(0.9)$ & $0(0)$ & $1(1.7)$ & 1 \\
\hline Skin & $5(4.3)$ & $2(3.4)$ & $3(5.2)$ & 1 \\
\hline Multiple sites & 38 (32.8) & $21(36.2)$ & $17(29.3)$ & 0.553 \\
\hline \multicolumn{5}{|l|}{ Underlying disease } \\
\hline Respiratory system & $14(12.1)$ & $8(13.8)$ & $6(10.3)$ & 0.776 \\
\hline Cardiovascular & $43(37.1)$ & $24(41.4)$ & $19(32.8)$ & 0.442 \\
\hline Kidney damage & $16(13.8)$ & $11(19)$ & $5(8.6)$ & 0.178 \\
\hline Liver damage & $13(11.2)$ & $3(5.2)$ & $10(17.2)$ & 0.077 \\
\hline Diabetes mellitus & $22(19)$ & $11(19)$ & $11(19)$ & 1 \\
\hline Tumors & $7(6)$ & $4(6.9)$ & $3(5.2)$ & 1 \\
\hline $\mathrm{sCr}(\mu \mathrm{mol} / \mathrm{L})$ & $116.5(69.5,211)$ & $\begin{array}{l}118.5(72.5 \\
263.5)\end{array}$ & $112.5(65.75,201)$ & 0.449 \\
\hline APACHE II score & $20(14,23)$ & $20(15,22.75)$ & $20(14,22.75)$ & 0.905 \\
\hline SOFA score & $8(5,10)$ & $8(5,10)$ & $8(5,9)$ & 0.92 \\
\hline $\begin{array}{l}\text { Mechanical } \\
\text { ventilation }\end{array}$ & $101(87.1)$ & $51(87.9)$ & $50(86.2)$ & 1 \\
\hline Vasoactive agents & $86(74.1)$ & $42(72.4)$ & $44(75.9)$ & 0.832 \\
\hline Septic shock & $60(51.7)$ & $34(58.6)$ & $26(44.8)$ & 0.193 \\
\hline
\end{tabular}




\begin{tabular}{|c|c|c|c|c|}
\hline duration (days) & $10(7,15)$ & $10(6,15.75)$ & $10(7,14)$ & 0.936 \\
\hline totaldose, mg & $1300(800,1925)$ & $1400(825,2100)$ & $1250(800,1650)$ & 0.321 \\
\hline Propensity score & $0.49 \pm 0.13$ & $0.49 \pm 0.13$ & $0.49 \pm 0.13$ & 0.975 \\
\hline \multicolumn{5}{|l|}{ Outcome } \\
\hline 30-day mortality & $42(36.2)$ & $22(37.9)$ & $20(34.5)$ & 0.847 \\
\hline $\begin{array}{l}\text { Total bacterial } \\
\text { clearance }\end{array}$ & $28(24.1)$ & $9(15.5)$ & $19(32.8)$ & 0.051 \\
\hline CRKP clearance & $40(34.5)$ & $13(22.4)$ & $27(46.6)$ & 0.011 \\
\hline $\begin{array}{l}\text { Hospitalization } \\
\text { duration (days) }\end{array}$ & $34(21,47.5)$ & $32(18,45)$ & $36.5(25.25,52.75)$ & 0.231 \\
\hline $\begin{array}{l}\text { Duration of ICU stay } \\
\text { (days) }\end{array}$ & $19(14,30)$ & $18(13.25,30)$ & $23(14,30)$ & 0.355 \\
\hline $\begin{array}{l}\text { Hospitalization cost } \\
\text { (\$, Thousand) }\end{array}$ & $\begin{array}{l}279251.5 \\
(197533.75 \\
448206.5)\end{array}$ & $\begin{array}{l}245616(167366 \\
372127.25)\end{array}$ & $\begin{array}{l}307852.5 \\
(220076.5, \\
515445.5)\end{array}$ & 0.039 \\
\hline $\mathrm{sCr}(\mu \mathrm{mol} / \mathrm{L})$ & $98.5(58.5,154)$ & $101(56.25,175.5)$ & $94(62.25,145)$ & 0.829 \\
\hline
\end{tabular}

sCr, Serum creatinine; TG, Tigecycline; PB, polymyxin; *, significant differences.

Table 4 Binary logistic regression with 30-day mortality

\begin{tabular}{|llll|}
\hline Endpoint & Variable & $P$ & OR, 95\% Cl \\
\hline 30-day mortality & Duration of vasoactive agents, (days) & & \\
& 1-4 vs. 0 (control) & $0.025^{\star}$ & $2.903(1.146-7.352)$ \\
\hline$>4$ vs. 0 (control) & $0.000^{\star}$ & $8.843(3.845-20.338)$ \\
\hline Therapy & & \\
\hline PB vs. TG (control) & 0.510 & $0.554(0.096-3.210)$ \\
\hline Duration of PB, (days) & & \\
\hline 4-8 vs. >8 (control) & $0.010^{*}$ & $2.974(1.297-6.820)$ \\
\hline CRKP clearance & $0.001 *$ & $0.312(0.159-0.612)$ \\
\hline
\end{tabular}

*, significant differences.

Table 5 Cox regression analysis for 30-day mortality 


\begin{tabular}{|c|c|c|}
\hline Variable & $P$ & $\mathrm{HR}, 95 \% \mathrm{Cl}$ \\
\hline \multicolumn{3}{|c|}{ 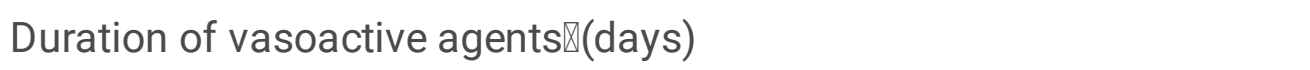 } \\
\hline $1-4$ vs. 0 (control) & $0.014^{\star}$ & $2.568(1.207-5.463)$ \\
\hline$>4$ vs. 0 (control) & $0.000 *$ & $5.746(2.982-11.074)$ \\
\hline \multicolumn{3}{|l|}{ Therapy } \\
\hline PB vs. TG (control) & 0.770 & $0.858(0.306-2.402)$ \\
\hline \multicolumn{3}{|c|}{ Duration of PB, (days) } \\
\hline 4-8 vs. >8 (control) & $0.000 *$ & $2.903(1.769-4.764)$ \\
\hline CRKP clearance & $0.000^{*}$ & $0.374(0.228-0.614)$ \\
\hline
\end{tabular}

*, significant differences.

\section{Figures}


(A)

Raw PB Group

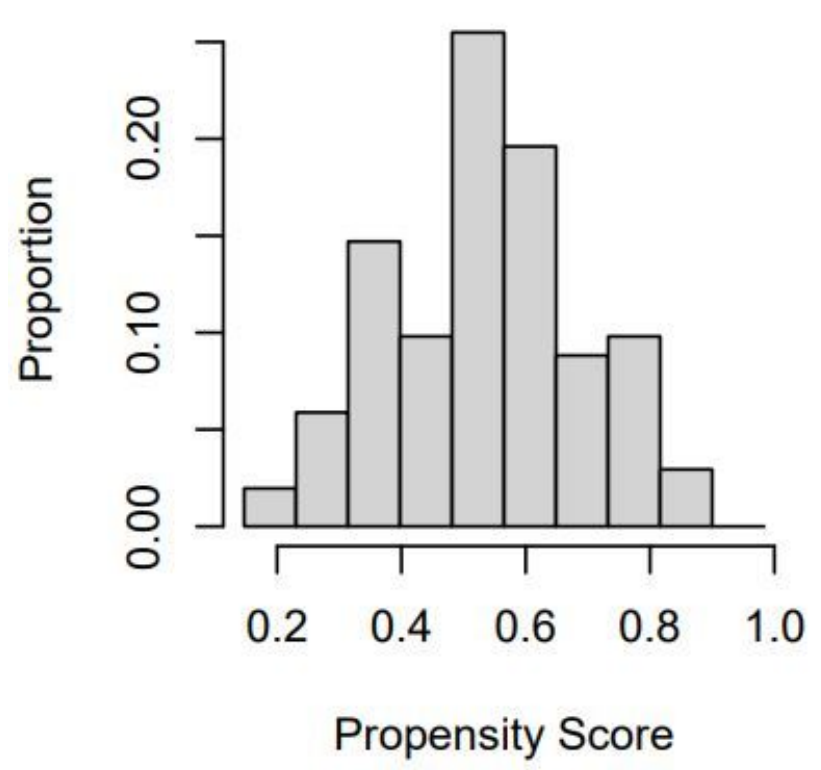

(C)

Raw TG Group

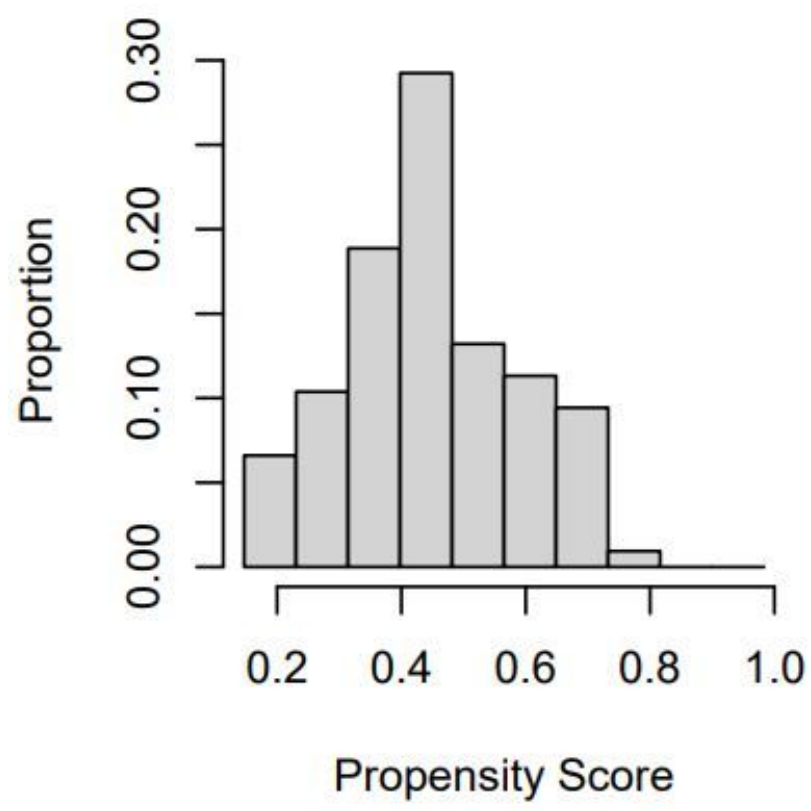

(B)

Matched PB Group

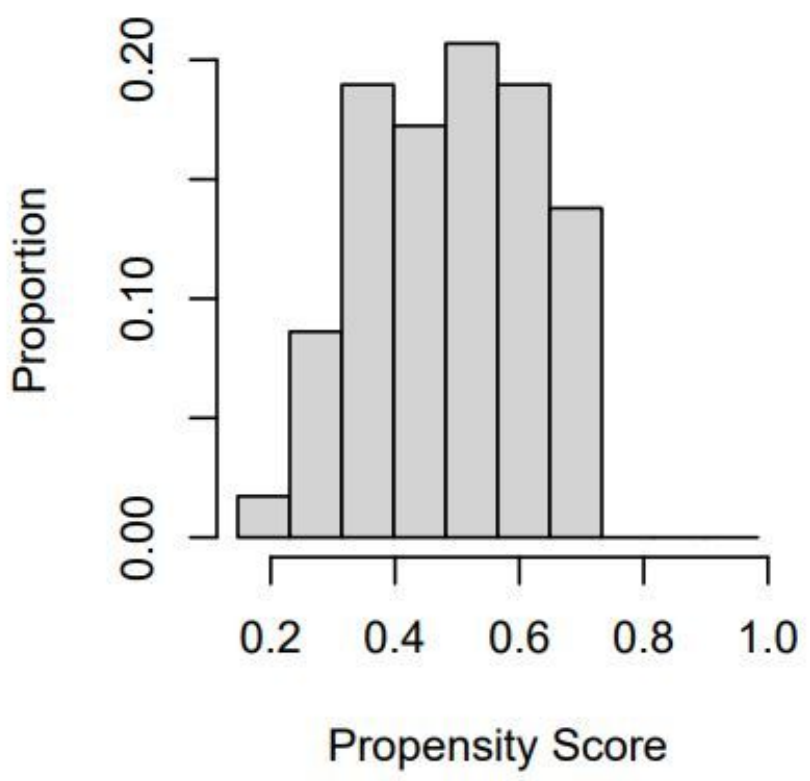

(D) Matched TG Group

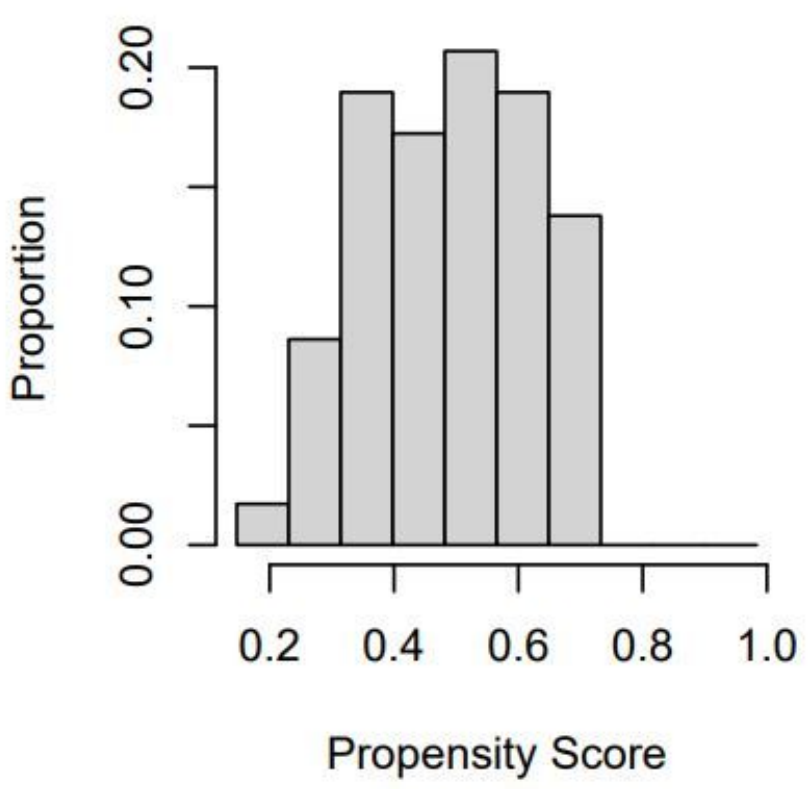

Figure 1

Distribution comparison of propensity scores before $(A, C)$ and after $(B, D)$ matching 


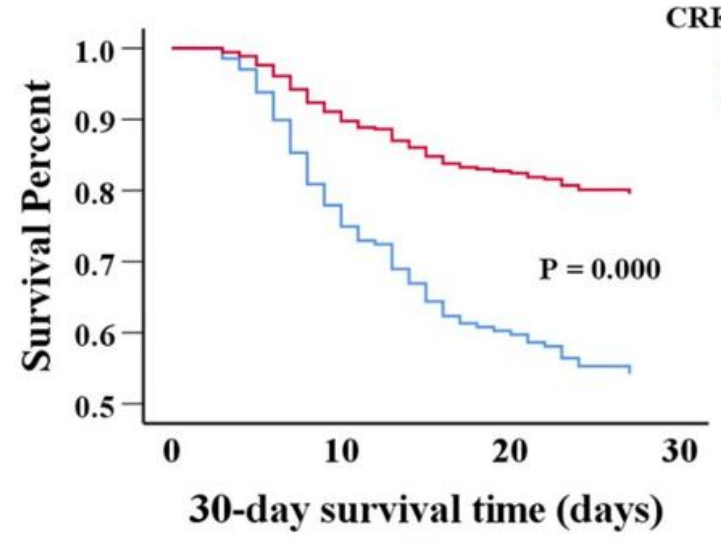

(A)

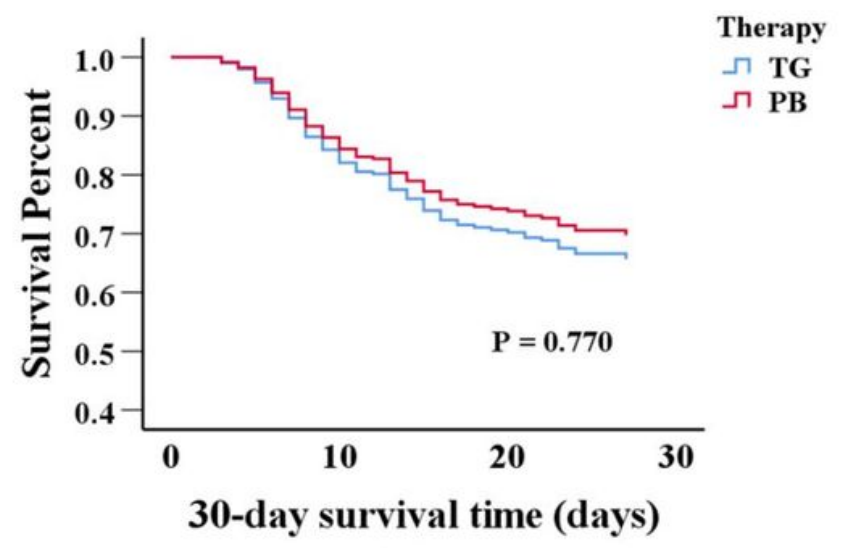

(C)

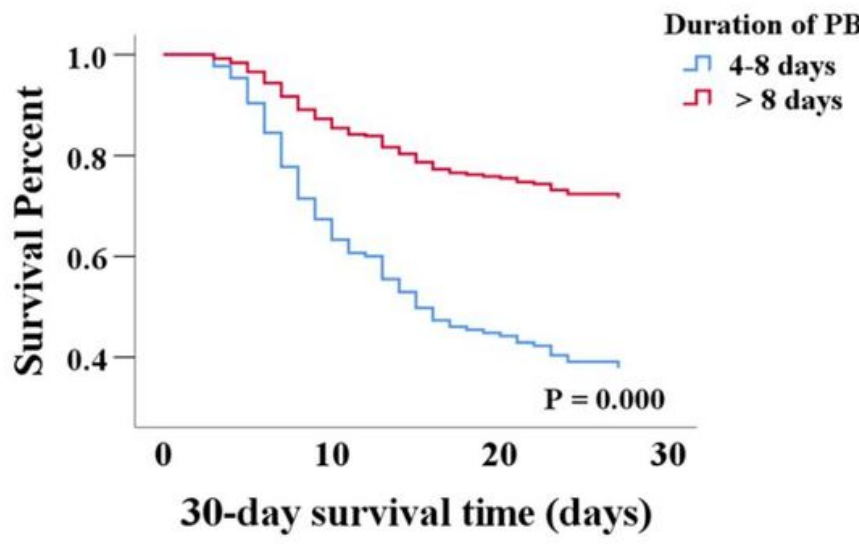

(B)

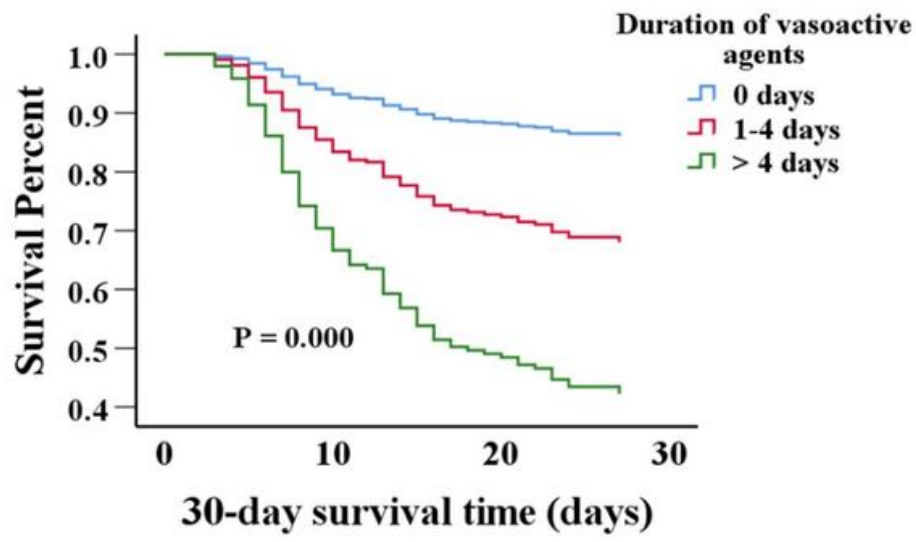

(D)

Figure 2

Cox-regression analysis for 30-day mortality

\section{Supplementary Files}

This is a list of supplementary files associated with this preprint. Click to download.

- SupplementaryTable1.docx 